\title{
Estrogenic Activity of Hyperforin in MCF-7 Human Breast Cancer Cells Transfected with Estrogen Receptor
}

Authors

Affiliations
Joseph Kwon ${ }^{1 *}$, Kyung Seo $\mathrm{Oh}^{2 *}$, Se-Young Cho ${ }^{2 *}$, Mi Ae Bang ${ }^{3 *}$, Hwan Seon Kim², Bipin Vaidya ${ }^{2,4}$, Duwoon Kim ${ }^{2,4,5}$

The affiliations are listed at the end of the article
Key words

- Clusiaceae

estrogenic activity

- hyperforin

- Hypericum perforatum

- Proteomics

- St. John's wort received April 30, 2016 revised June 29, 2016 accepted July 8, 2016

\section{Bibliography}

DOI http://dx.doi.org/ 10.1055/s-0042-112594

Published online July 25, 2016 Planta Med 2016; 82:

1425-1430 @ Georg Thieme Verlag KG Stuttgart - New York . ISSN 0032-0943

\section{Correspondence \\ Duwoon Kim}

Department of Food Science and Technology

Chonnam National University

77 Yongbong-ro, Buk-gu

Gwangju 61186

Republic of Korea

Phone: +82625302144

Fax: + 82625302149

dwkim@jnu.ac.kr

\section{Correspondence}

Bipin Vaidya

Department of Food Science

and Technology

Chonnam National University

77 Yongbong-ro, Buk-gu

Gwangju 61186

Republic of Korea

Phone: +82625300662

Fax: + 82625302149

bipin@jnu.ac.kr

\section{Abstract}

\section{$\nabla$}

Hyperforin, a major active compound of St. John's wort extract, affects estrogenic activity. In this study, the compound evoked estrogen response element-dependent luciferase activity and cell proliferation in MCF-7 cells. Hyperforin-induced cell proliferation was significantly inhibited by the estrogen receptor antagonist ICI 182,780. These results suggested that hyperforin had estrogenic and cell proliferation activities, which were stimulated via the estrogen receptor. Compared to $17 \beta$-estradiol, hyperforin showed significantly lower estrogenic activity and cell proliferation. The mechanism underlying the estrogenic activity of hyperforin was unknown, therefore, in this study, for the first time, the expression and post-translational modification of proteins were determined and compared among control, 17 $\beta$ estradiol-treated, and hyperforin-treated cells using proteomic techniques. A total of 453 proteins were identified, of which 282 proteins were significantly modulated in hyperforin-treated cells compared to $17 \beta$-estradiol-treated cells. Ingenuity pathway analysis also demonstrated that hyperforin treatment induced less cell proliferation than $17 \beta$-estradiol by downregulating estrogen receptor 1 . Protein network analysis showed that cell proliferation was regulated mainly by cyclin

\section{Introduction}

$\nabla$

Estrogens play important roles in reproductive physiology and multiple diseases, including breast and endometrial cancers, cardiovascular disease, osteoporosis, and Alzheimer's disease [1, 2 ]. The most active form of endogenous estrogen, $17 \beta$-E2, is mostly synthesized in the ovaries of

\footnotetext{
${ }^{*}$ These authors contributed equally to this work.
}

D1 and extracellular signal-regulated kinases. In conclusion, although, hyperforin exhibited lower estrogenic activity than $17 \beta$-estradiol, the compound induced lower levels of cancer cell proliferation in vitro.

\section{Abbreviations \\ $\nabla$ \\ 17 $\beta$-E2: $\quad 17 \beta$-estradiol \\ AKR1C3: aldo-keto reductase family 1 member C3 \\ CAT: $\quad$ catalase \\ CCND1: $\quad$ cyclin D1 \\ CTSD: cathepsin D \\ ERE: estrogen response element \\ ERK: extracellular signal-regulated kinases \\ ESR: estrogen receptor \\ IL6ST: interleukin-6 signal transducer \\ NOX: NADPH oxidase \\ NUMA: nuclear mitotic apparatus protein 1 \\ PRDX1: $\quad$ peroxiredoxin 1 \\ PRDX2: $\quad$ peroxiredoxin 2 \\ PRDX6: $\quad$ peroxiredoxin 6 \\ PTM: $\quad$ post-translational modification \\ SJW: $\quad$ St. John's wort}

Supporting information available online at http://www.thieme-connect.de/products

premenopausal women. To exert its effect, $17 \beta$ E2 binds to specific ESR1 and ESR2, after which the activated estrogen-ESR complex is transported to the nucleus, where it binds to the ERE in the promoter regions of estrogen-dependent genes, thereby altering gene expression [3]. The maintenance of appropriate levels of estrogen is important for reducing post-menopausal symptoms; however, the hypoestrogenic state is associated with an increased risk of cardiovascular disease, osteoporosis, and complications in preg- 
nancy and lactation, while the hyperestrogenic state promotes cancer cell proliferation $[4,5]$.

Estrogen replacement therapy (ERT) appears to reduce the risk of osteoporosis, colorectal cancer, and the severity of postmenopausal symptoms [6-9]. Nevertheless, the safety of ERT is a major concern due to the higher incidence of breast cancer, cardiovascular disease, and stroke among postmenopausal women undergoing therapy [8-10]. In this respect, phytoestrogens, a diverse group of plant-derived nonsteroidal compounds that mimic $17 \beta$-E2 because of their structural similarity to mammalian estrogens, could be alternatives to conventional ERT [11]. Phytoestrogens, including glycinol in soybean and resveratrol in grapes, are reported to exert estrogenic effects $[12,13]$. Lignans are thought to exert protective effects against cancer; however, the anticancer effects of glabridin, genistein, quercetin, and resveratrol are inconsistent [14-16]. Furthermore, phytoestrogens act as both estrogen agonists and antagonists, and differ in their levels of estrogenic activity $[17,18]$. In addition, herbal plants, such as kudzu root, chasteberry, red clover, hops, and agrimony, show estrogenic activities in the uterus and in breast cancer cell lines [19-21]. Among those, hops and red clover contain 8-prenylnaringenin and genistein, respectively, as the major estrogenic compounds [21,22]. Ginseng, which contains ginsenosides as active compounds, prevents postmenopausal osteoporosis and cancer cell proliferation by modulating ESR 1 activity $[23,24]$.

SJW (Hypericum perforatum L., Clusiaceae) contains several bioactive compounds, the main ones being hyperforin and hypericin. SJW extract has been reported to have a therapeutic effect on mild-to-moderate depression, relieve the psychological and psychosomatic symptoms of menopause, and possess antimicrobial, anti-inflammatory, antioxidant, and free radical scavenging properties [25-28]. Hypericin has been found to show antiretroviral activity, while hyperforin has antidepressant and antiinflammatory activities [29-31]. Moreover, several studies evaluated the role and mechanism of SJW for the treatment of estrogen-mediated menopausal symptoms. A previous study reported that SJW regulates the genes related to antidepressant activity [32]. Liu et al. presented the possible mechanisms of SJW extract for the reduction of menopausal symptoms, including depression and hot flashes [33]. Although many studies have dealt with the estrogen-related activities of SJW and its constituents, the mechanisms of the activities of hyperforin have not yet been fully characterized.

In the present study, we assessed the estrogenic activities of hyperforin by measuring evoked ERE-luciferase activity and cell proliferation in MCF-7 cells. In addition, we used proteomic approaches to examine the modulation of proteomic profiles and their post-translational modifications in cells treated with hyperforin and $17 \beta$-E2 to identify the underlying mechanism.

\section{Results and Discussion}

$\nabla$

The components of SJW extract were separated as a total ion chromatogram using UFLC-MS (Fig. 1S A, Supporting Information). To confirm the identification, the electrospray ionization (ESI) mass spectra of the compound was obtained from the sample under similar operating conditions, and was found to be comparable to the spectra of the authentic reference sample. Among the different peaks, the largest peak area was identified as hyperforin (denoted by the green chromatogram) and had a retention time of 9.0. The mass spectra for hyperforin showed ionic species



Fig. 1 Effects of St John's wort (SJW) extract, hyperforin (HF), and 17 $\beta$ estradiol (17 $\beta$-E2) on ERE-luciferase activity in MCF-7 cells. The luciferase activities in MCF-7 cells transfected with $\operatorname{ER} \alpha(\mathbf{A}, \mathbf{C})$ or $\operatorname{ER} \beta(\mathbf{B}, \mathbf{D})$ and an ERE reporter plasmid were measured after treatment with 0.2 to $20 \mu \mathrm{g} / \mathrm{mL} \mathrm{SJW}$ extract (A, B) or $10^{-5}$ to $10 \mu \mathrm{M} \mathrm{HF}(\mathbf{C}, \mathbf{D})$. A positive control was prepared by treating the cells with $10^{-2} \mu \mathrm{M} 17 \beta$-E2. Relative luciferase activities were calculated as percentages of the induced luminance relative to control after normalization to the Renilla luciferase activity. Bars represent the averages of triplicate determinations. Asterisks indicate significant differences from the control (Ctrl) determined using Dunnett's multiple comparison t-test $\left({ }^{*} \mathrm{p}<0.05\right.$ and $\left.{ }^{* * *} \mathrm{p}<0.001\right)$.

at $\mathrm{m} / \mathrm{z} 535.4$ (Fig. 1S A, B, Supporting Information), which confirms its presence in SJW. The amount of hyperforin and hypericin in the extract was $3.5 \mathrm{mg} / \mathrm{g}$ and $2.6 \mathrm{mg} / \mathrm{g}$, respectively. The estrogenic activities of SJW extract and hyperforin in MCF-7 cells transfected with ESR1 or ESR2 were tested using ERE-luciferase activity assays. The results are expressed as percentages of relative luciferase activity (RLA) compared to the untreated control, and for comparison, a positive control was also prepared by treating the transfectants with $10^{-2} \mu \mathrm{M} 17 \beta$-E2. The RLA of the transfected cells after treatment with SJW extract ( 0.2 to $20 \mu \mathrm{g} /$ $\mathrm{mL}$ ) and hyperforin $\left(10^{-5}\right.$ to $\left.10 \mu \mathrm{M}\right)$ is shown in 0 Fig. 1. Both samples significantly increased the RLA in cells transfected with ESR1 or ESR2 in a concentration-dependent manner. At a concentration of $20 \mu \mathrm{g} / \mathrm{mL}$, SJW extract elicited responses that were 1.3fold smaller (RLA: $311.2 \%$ vs. $412.9 \%$ ) or 2.0 -fold larger (297.8\% vs. $146.7 \%$ ) than those elicited by $10^{-2} \mu \mathrm{M} 17 \beta$-E2 in ESR1 or ESR2 transfectants, respectively ( $\mathbf{O F i g . 1} \mathbf{A}, \mathbf{B})$. In contrast, irrespective of whether the cells were transfected with ESR1 or ESR2, RLA levels elicited by $10^{-2} \mu \mathrm{M}$ hyperforin (RLA: ESR1, $252.8 \%$ and ESR2, $63.4 \%$ ) were lower than those elicited by the same concentration of $17 \beta$-E2 (RLA: ESR1, $412.9 \%$ and ESR2, $146.7 \%$ ) (O Fig. 1C,D). This finding is consistent with that of Harris et al. who observed a difference between RLAs elicited by $17 \beta$-E2 and phytoestrogen in breast cancer cells transfected with either ESR1 or ESR2 [34].

- Fig. 2 shows the concentration-dependent effects of the SJW extract, hyperforin, and $17 \beta$-E2 on the proliferation of MCF-7 cells. SJW extract induced cell proliferation with a $50 \%$ effective concentration $\left(\mathrm{EC}_{50}\right)$ of $2.1 \mu \mathrm{g} / \mathrm{mL}$ and maximum response $\left(\mathrm{E}_{\max }\right)$ of $124.7 \%$ of the control ( $\mathrm{Fig} .2 \mathrm{~A}$ ). The $\mathrm{EC}_{50}$ of hyperforin and $17 \beta$-E2 was $3.3 \times 10^{-3} \mu \mathrm{M}$ and $1.8 \times 10^{-2} \mu \mathrm{M}$, respectively, indicat- 
ing that the $\mathrm{EC}_{50}$ of hyperforin was lower than that of $17 \beta$-E2. Similarly, the $\mathrm{E}_{\max }$ of hyperforin was lower than that of $17 \beta$-E2 ( $E_{\text {max }}$ : hyperforin, $112.7 \%$ vs. $17 \beta$-E2, 128.5\%). These results indicated that hyperforin possessed lower potency $\left(\mathrm{EC}_{50}\right.$ value) and efficacy ( $E_{\max }$ value) to that of $17 \beta$-E2 for inducing cell proliferation (๑ Fig. 2 B).

To determine whether the cell proliferation induced by SJW extract and hyperforin reflected their estrogenic activities, we next examined the effects of the ER antagonist ICI 182,780 on the response. The proliferation of cells treated with SJW extract ( $20 \mu \mathrm{g} /$ $\mathrm{mL})$ and hyperforin $(10 \mu \mathrm{M})$ increased significantly when compared to the control cells in the absence of ICI 182,780 ( $p=0.000$ and $\mathrm{p}=0.001$, respectively). However, we found that the ER antagonist ICI 182,780 significantly inhibited cell proliferation induced by the same concentration of SJW extract and hyperforin by $16.9 \%(p=0.000)$ and $6.6 \%(p=0.007)$, respectively, when compared to the corresponding sample without ICI 182,780 ( Fig.3), indicating that the induced cell proliferation was related to their estrogenic activities. Notably, ICI 182,780 had a 1.2-fold and 3.1-fold stronger effect on 17 $\beta$-E2-induced proliferation than it did on SJW-induced and hyperforin-induced proliferation, respectively. The inhibitory effect of ICI 182,780 on $17 \beta$ E2-induced cell proliferation has also been reported in the rat uterus, which could be due to multiple steps, including binding to the ESR by ICI 182,780 followed by disrupting ESR nuclear localization, and reducing binding of ESR to ERE $[35,36]$.

Proteomic profiles of three samples, including control, 17 $\beta$-E2treated, and hyperforin-treated cells, were generated by nanoUPLC-MS analysis. A total of 453 proteins were identified in the three samples, and among them, 282 proteins were differentially modulated in the hyperforin-treated cells compared to the $17 \beta$ E2-treated cells (Table 1S, Supporting Information). The proteomic data were further integrated into a knowledge database supported by Ingenuity pathway analysis (IPA) to visualize the interaction network composed of identified and predicted proteins. - Fig. 4 shows the networks of proteins that were differentially expressed in response to hyperforin treatment relative to $17 \beta$ E2 treatment in MCF-7 cells. Mainly, hyperforin was predicted to be more inhibitive of ESR1 activity than $17 \beta$-E2, leading to the downregulation of cell proliferation. However, hyperforin was predicted to activate ESR2 activity, leading to the reduced production of reactive oxygen species (ROS).

In our study, cell proliferation-related proteins, mainly CCND1, ERK, IL6ST, and AKR1C3, were downregulated by hyperforin treatment compared to $17 \beta$-E2 treatment, indicating that hyperforin less likely leads to cancer progression. A previous study reported that activation of ESR 1 by $17 \beta$-E2 treatment subsequently triggered ERK signaling, which supported the upregulation of the expression of CCND1 and further induced cell proliferation [37, 38]. Similar to CCND1, CTSD, a prognostic biomarker of cancer cell proliferation, was downregulated by hyperforin compared to17 $\beta$-E2 [39]. Downregulation of IL6ST by hyperforin suggests that hyperforin abrogates cancer cell proliferation by impairing CCND1 and ERK expression. Furthermore, 17 $\beta$-E2-stimulated AKR1C3 also was downregulated by hyperforin, which suggests that cell proliferation is inhibited by controlling the activities of estrogen and progesterone [40]. AKR1C3 induces cell proliferation by catalyzing the reaction either to reduce estrone to the more potent $17 \beta$-E2 or to reduce progesterone to the less potent pregnanediol [41]. AKR1C3 controls concentrations of estrogens and progesterone, which further regulates the activities of ESR1 and ESR2.



Fig. 2 Concentration-response curves of St. John's wort (SJW) extract, hyperforin, and $17 \beta$-estradiol for MCF-7 cell proliferation. MCF-7 cells were cultured in estrogen-free medium, treated with $0.2-20 \mu \mathrm{g} / \mathrm{ml} \mathrm{SJW}$ extract or with $10^{-5}-10 \mu \mathrm{M}$ of hyperforin or $17 \beta$-estradiol. Cell proliferation was determined using the Cell Counting Kit- 8 , and calculated as percentage of cell proliferation relative to untreated control. The curves of cell proliferation versus logarithm of concentration of SJW extract (A), hyperforin, or $17 \beta$-estradiol (B) were plotted. The curves represent the averages of five determinations expressed as percentages.

To protect against the harmful consequences of oxidative stress, IPA predicted that a number of prooxidant and antioxidant enzymes, including CAT, NOX, PRDX1, and PRDX6 were modulated by hyperforin and $17 \beta$-E2 through the activation of ESR2. Hyperforin and $17 \beta$-E2 affect oxidative stress by increasing CAT activity, which is dependent on the ratio of ESR1 and ESR2 in the cancer cell. Moreover, hyperforin, similar to other phytoestrogens, acts as an inhibitor of NOX, resulting in the decreased production of ROS via ESR2 [42]. IPA also showed that the activity of NOX is dependent on PRDX6 [43]. Hyperforin suppressed PRDX6 expression, which subsequently decreased NOX activity. Additionally, IPA indicated that the hyperforin-induced activation of ESR2 reduced oxidative stress relative to $17 \beta$-E2. A previous study also reported that a low ESR1/ESR2 ratio is a hallmark for the protection of cancer cells against oxidative stress [44].

Along with protein expression, ER function is also regulated by PTMs of the proteins. In this study, proteomic analysis identified 59 post-translationally modified proteins. Among the PTMs, phosphorylation, acetylation, and oxidation were observed in 47,15 , and 3 proteins, respectively. Proteins that were phosphorylated or acetylated included heat shock protein 90B (HSP90B), PRDX2, and isoform 2 of the NUMA, which are all involved in cell proliferation and ROS production (Fig. 45 and Table 2S, Supporting Information). However, notably, phosphorylation of NUMA was significantly inhibited by hyperforin treatment when compared to $17 \beta$-E2 treatment (hyperforin/17 $\beta$-E2 ratio, 0.867). NUMA is crucial for mitotic spindle formation during progression of the cell cycle. Localization of NUMA to the mitotic spindle is regulated by its phosphorylation, which transforms NUMA into a soluble component of the mitotic pole at the onset of mitosis [45]. Our PTM analysis showed lower levels of phosphorylated NUMA in hyperforin-treated cells than in 17 $\beta$-E2-treated cells, indicating that cancer cell proliferation was inhibited by blocking mitosis.

A limitation of this study is that our in vitro findings represent a portion of the animal's metabolic system, and does not address the bioavailability of the compounds. The effects of a compound in an in vitro study may not be directly replicated in an animal model. Therefore, these compounds that showed estrogenic potential in vitro need to be tested in vivo for their efficacy. 
In conclusion, hyperforin can mimic the estrogenic activity of $17 \beta$-E2 by showing comparable effects on ERE-luciferase activity in vitro, in MCF-7 cells. In this study, for the first time, we attempted to identify comparative protein expression in hyperforin and $17 \beta$-E2 treatment. The expression of proteins related to cell proliferation and ROS production was differentially regulated. Hyperforin treatment induced less cancer cell proliferation than $17 \beta$-E2 treatment, possibly by downregulating CCND1 and ERK expression through ESR1. At the same time, hyperforin-treated cells showed lower rates of ROS production than 17 $\beta$-E2-treated cells, possibly by the downregulation of NOX through ESR2. Hence, this study will aid in the identification and development of a safe alternative method for estrogenic regulation for the purpose of reducing postmenopausal symptoms in women.

\section{Materials and Methods \\ $\nabla$}

\section{Sample preparation}

The leaves and flowers of SJW obtained from a local producer (Cooperative of Daeho-dong, Naju, Korea) were used for this study because the compounds, including hyperforin, hypericin, chlorogenic acid, hyperoside, and quercetin, are mainly present in those parts of the plant [46]. A voucher specimen (identification number: JBF-FRI-B-2012-0001) of the plant used in our experiment was deposited at the Jeonnam Biofood Technology Center, Korea. First, $500 \mathrm{~g}$ of dried leaves and flowers of SJW were extracted in $5 \mathrm{~L}$ of $75 \%$ ethanol for $8 \mathrm{~h}$ and extracted again in $2.5 \mathrm{~L}$ $75 \%$ ethanol for $5 \mathrm{~h}$, with stirring in the dark. The resultant mixture was filtered through a bag filter $(1 \mu \mathrm{m})$, after which the solvent was evaporated at $42{ }^{\circ} \mathrm{C}$ using a rotary vacuum evaporator (Daesin Machine Industry). The remaining extract was then freeze-dried, packed into screw-capped vials under nitrogen, and stored at $-20^{\circ} \mathrm{C}$ for later use. Stock solutions of SJW extract and $17 \beta$-E2 (Sigma Aldrich, purity $\geq 98 \%$ ) were prepared in DMSO (purity $\geq 99.7 \%$, Sigma-Aldrich) at concentrations of $200 \mu \mathrm{g} / \mathrm{mL}$ and $10 \mathrm{mM}$, respectively. Stock solutions of hyperforin (Cayman Chemical Co., purity $\geq 90 \%$ ) were prepared in methanol and stored at $-20^{\circ} \mathrm{C}$.

\section{Transient transfection and luciferase activity assay}

For transient transfection, MCF-7 cells (Korean Cell Line Bank) were cultured in DMEM/Nutrient Mixture F-12 medium (DMEM/F-12, Gibco Life Technologies) supplemented with $10 \%$ fetal bovine serum, $100 \mathrm{U} / \mathrm{mL}$ penicillin, $100 \mathrm{U} / \mathrm{mL}$ streptomycin, and $1 \%$ bovine insulin as previously described [20]. The cells were plated in 96-well plates at a density of $2.0 \times 10^{4}$ cells/well. After $24 \mathrm{~h}$, the cells was transfected using FuGENEHD transfection reagent (Promega) according to the manufacturer's protocol. Briefly, Opti-MEM was used to dilute ER $\alpha$ (pEGFP-C1-ER $\alpha$, Addgene), ER $\beta$ (pcDNA Flag ER $\beta$, Addgene), ERE ( $3 \times$ ERE TATA luc, Addgene), and Renilla luciferase (pRL-SV40, Promega) prior to the addition of the transfection reagent. The cells were incubated for $24 \mathrm{~h}$ at $37^{\circ} \mathrm{C}$ under a humidified 5\% $\mathrm{CO}_{2}$ atmosphere $[47,48]$ in phenol red-free DMEM/F-12 containing $5 \%$ charcoaldextran stripped fetal bovine serum with $0.2,2.0$, or $20 \mu \mathrm{g} / \mathrm{mL}$ SJW extract or $10^{-5}, 10^{-2}$, or $10 \mu \mathrm{M}$ hyperforin. Following the incubation, the cells were washed twice with PBS and lysed in $20 \mu \mathrm{L}$ of passive lysis buffer (Promega). Luciferase activity was then measured using Luciferase Assay Reagent (Promega) in a GloMax Multi Microplate Luminometer (Promega) according to the manufacturer's protocol. The RLA was calculated as previously de-

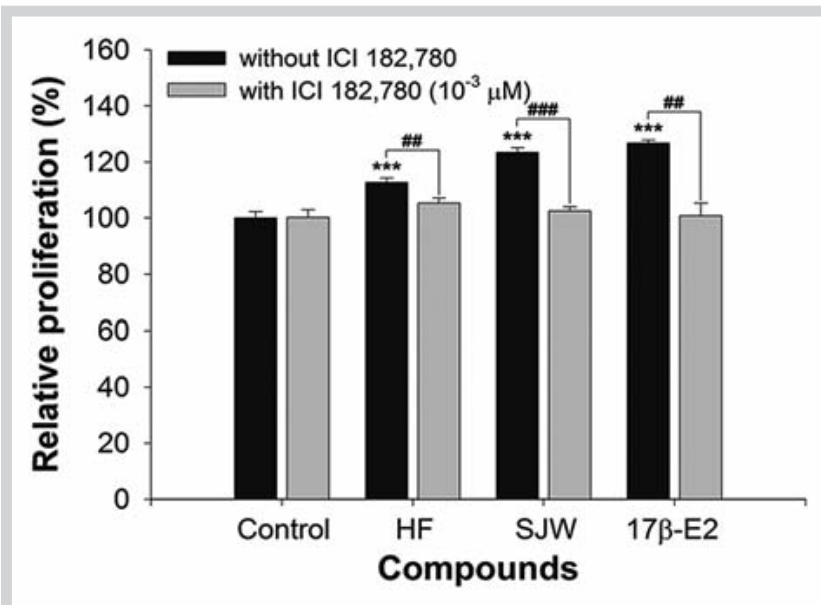

Fig. 3 Inhibitory effect of ICI 182,780 on MCF-7 cell proliferation induced by St. John's wort (SJW) extract, hyperforin (HF), or 17 $\beta$-estradiol (17 $\beta$-E2). MCF-7 cells were cultured for $96 \mathrm{~h}$ in estrogen-free medium and treated with $20 \mu \mathrm{g} / \mathrm{mL}$ of SJW extract, $10 \mu \mathrm{M} \mathrm{HF}$, or $10 \mu \mathrm{M} 17 \beta$-E2 in the presence and absence of ICI 182,780. Cell counts were normalized to an untreated control sample. Bars represent the averages of triplicate determinations expressed as percentages. Asterisk $\left({ }^{*}\right)$ indicates significant differences when compared to the untreated control (without ICI 182,780) determined using Dunnett's multiple comparison-test ( $\left.{ }^{* *} p<0.001\right)$, and hash (\#) indicates significant difference when compared to the corresponding sample without ICI 182,780 (\#\#p < 0.01 and \#\#\#p < 0.001) determined using Student's t-test.

scribed [49]. The positive control was prepared by treating the cells with $10^{-2} \mu \mathrm{M} 17 \beta$-E2, while the negative control was prepared by using the vehicle solvent only.

\section{Cell proliferation assay}

MCF-7 cells were seeded into 96-well microplates at a density of $5 \times 10^{3}$ cells/well in culture medium. After $24 \mathrm{~h}$, the medium was replaced with estrogen-free, phenol red-free DMEM/F-12 containing 5\% charcoal-dextran-stripped fetal bovine serum. Different concentrations of SJW extract or hyperforin were added to the medium as described in the luciferase activity assay, and the cells were cultured for $96 \mathrm{~h}$. In addition, to investigate the effect of an estrogen antagonist, duplicate test samples were prepared using $20 \mu \mathrm{g}$ SJW extract, $10 \mu \mathrm{M}$ hyperforin, and $10 \mu \mathrm{M} 17 \beta$-E2, with or without the ER-antagonist ICI $182,780\left(10^{-3} \mu \mathrm{M}\right.$, Santa Cruz Biotechnology, purity $\geq 98 \%$ ). The positive control was prepared by treating the cells with $10^{-5}, 10^{-2}$, and $10 \mu \mathrm{M} 17 \beta$-E2, while the negative control was prepared by using the vehicle solvent only [20]. Cell proliferation was assessed using a Cell Counting Kit-8 (Dojindo) as described by Nakagawa et al. [50]. The proliferation was expressed as a percentage compared to the negative control. Concentration-response curves were plotted and the $\mathrm{EC}_{50}$ and $\mathrm{E}_{\max }$ were estimated using GraphPad Prism version 5.01 (GraphPad Software, Inc.).

\section{Protein extraction and tube-gel protein digestion}

Proteins were extracted as previously described [51]. The protein was quantified using a Detergent Compatible Protein Assay Kit (Bio-Rad). A tube-gel digestion protocol was adopted as described previously [51]. 


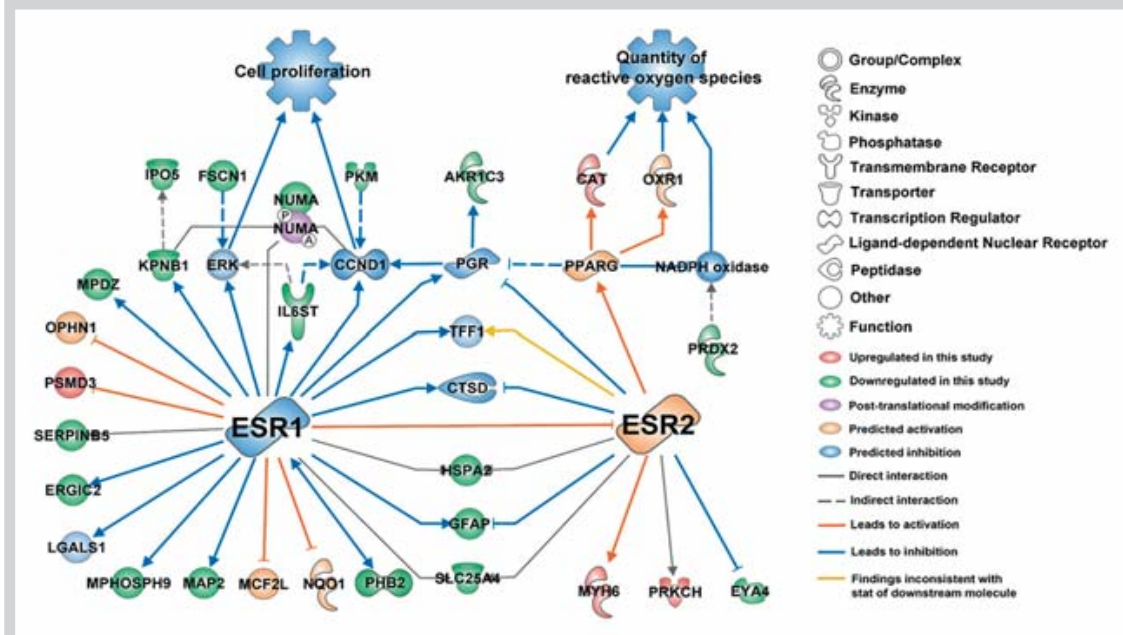

Fig. 4 Network derived with comparing proteins expressed in hyperforin-treated and $17 \beta$-estradiol (17 $\beta$-E2)-treated MCF-7 cells. The proteins shown in Tables 15 and 2S, Supporting Information, were imported into IPA, and specific proteins related to cell proliferation and ROS generation were selected for the network using the Ingenuity knowledge database. Significantly upregulated and downregulated ( $p$ value $<0.05$ ) proteins in hyperforin-treated cells compared to $17 \beta$-E2-treated cells are shown in red and green, respectively. The proteins, which were predicted to be activated and inhibited, are shown in orange and blue, respectively. Post-translational modification, phosphorylation (P), and acetylation (A) of proteins are indicated by enclosed text. (Color figure available online only.)

\section{Nano-UPLC-HDMSE}

Tryptic peptide mixtures were separated using nano-ACQUITY ultra-performance liquid chromatograph (UPLC) equipped with a Synapt G2-Si HDMS System (Waters Corp.), a previously described method with optimization of the mobile phase system [51]. A gradient elution program was conducted for chromatographic separation with mobile phase A $0.1 \%$ formic acid in water) and mobile phase B ( $0.1 \%$ formic acid in acetonitrile) as follows: $97 \%$ mobile phase A initially, $90 \%$ mobile phase A for $3 \mathrm{~min}, 65 \%$ mobile phase A for $150 \mathrm{~min}$, gradual decrease to $20 \%$ mobile phase A over $160 \mathrm{~min}$, and a sharp increase to $97 \%$ mobile phase $A$ for the last $10 \mathrm{~min}$.

\section{Identification and relative quantification of protein}

For identification of proteins, MS spectra of peptides were aligned using Progenesis QI for Proteomics (QIP) version 2.0 (Nonlinear Dynamics), a previously adopted method with modifications in criteria for protein identification [51], and the spectra were matched to human proteins using the International Protein Index (IPI) human database (v.3.87). The criteria for protein identification were set as follows: $\geq 3$ fragment per peptide, $\geq 7$ fragments per protein, and $\geq 2$ peptides per protein. Carbamidomethylation of cysteine was set as fixed, and oxidation of methionine and phosphorylation of serine/threonine/tyrosine were set as variable modifications.

\section{Bioinformatics analysis}

Ingenuity pathway analysis (IPA version 9.0; Ingenuity Systems, Inc.) was used to perform knowledge-based network analysis of proteomics data.

\section{Data analysis}

Data are shown as the mean \pm SD. All experiments were performed in triplicate. Statistical significance among multiple treatment groups was determined by one-way analysis of variance (ANOVA) followed by Dunnett's multiple comparison test. Student's t-test was performed for comparison between two treatment groups. The analysis was performed using SPSS Version 21 (IBM). A difference was considered statistically significant at $\mathrm{p}<0.05$.

\section{Supporting information}

A list of proteins and mean relative ratios, a list of PTM, target peptide sequence of modified proteins, and mean relative ratios, ion chromatogram and mass spectra of compounds present in St. John's wort extract, networks derived comparing proteins expression, and three-dimensional spectra are available as Supporting Information.

\section{Acknowledgements}

This research was financially supported by the Ministry of Trade, Industry, \& Energy (MOTIE), the Korea Institute for Advancement of Technology (KIAT), the Honam Institute for Regional Program Evaluation through the Leading Industry Development for Economic Region, and Priority Research Centers Program through the National Research Foundation of Korea (NRF), funded by the Ministry of Education, Science, and Technology (Grant No. 20100020141).

\section{Conflict of Interest \\ $\nabla$}

The authors declare no conflict of interest.

\section{Affiliations}

${ }^{1}$ Korea Basic Science Institute, Daejeon, Republic of Korea

2 Department of Food Science and Technology and BK21 Plus Program,

Chonnam National University, Gwangiu, Republic of Korea

${ }^{3}$ Jeonnam Biofood Technology Center, Naju, Republic of Korea

${ }^{4}$ Bioenergy Research Center, Chonnam National University, Gwangju, Republic of Korea

${ }^{5}$ Foodborne Virus Research Center, Chonnam National University, Gwangju, Republic of Korea

\section{References}

1 Heldring N, Pike A, Andersson S, Matthews J, Cheng G, Hartman J, Tujague $M$, Ström A, Treuter E, Warner M, Gustafsson JA. Estrogen receptors: how do they signal and what are their targets. Physiol Rev 2007; 87: 905-931

2 Nilsson S, Mäkelä S, Treuter E, Tujague M, Thomsen J, Andersson G, Enmark E, Pettersson K, Warner M, Gustafsson JA. Mechanisms of estrogen action. Physiol Rev 2001; 81: 1535-1565

3 Marino M, Galluzzo P, Ascenzi P. Estrogen signaling multiple pathways to impact gene transcription. Curr Genomics 2006; 7: 497-508

4 Dalal PK, Agarwal M. Postmenopausal syndrome. Indian J Psychiatry 2015; 57: S222-S232 
5 Zanetta GM, Webb MJ, Li H, Keeney GL. Hyperestrogenism: a relevant risk factor for the development of cancer from endometriosis. Gynecol Oncol 2000; 79: 18-22

6 Grodstein F, Manson JE, Colditz GA, Willett WC, Speizer FE, Stampfer MJ. A prospective, observational study of postmenopausal hormone therapy and primary prevention of cardiovascular disease. Ann Intern Med 2000; 133: 933-941

7 Moreira AC, Silva AM, Santos MS, Sardão VA. Phytoestrogens as alternative hormone replacement therapy in menopause: What is real, what is unknown. J Steroid Biochem Mol Biol 2014; 143: 61-71

8 Warren MP. A comparative review of the risks and benefits of hormone replacement therapy regimens. Am J Obstet Gynecol 2004; 190: 11411167

9 Davis SR, Lambrinoudaki I, Lumsden M, Mishra GD, Pal L, Rees M, Santoro N, Simoncini T. Menopause. Nat Rev Dis Primers 2015; 1: 15004

10 Chen CL, Weiss NS, Newcomb P, Barlow W, White E. Hormone replacement therapy in relation to breast cancer. JAMA 2002; 287: 734-741

11 Borrelli $F$, Ernst E. Alternative and complementary therapies for the menopause. Maturitas 2010; 66: 333-343

12 Boué SM, Tilghman SL, Elliott S, Zimmerman MC, Williams KY, PaytonStewart F, Miraflor AP, Howell MH, Shih BY, Carter-Wientjes CH, Segar C, Beckman BS, Wiese TE, Cleveland TE, McLachlan JA, Burow ME. Identification of the potent phytoestrogen glycinol in elicited soybean (Glycine max). Endocrinology 2009; 150: 2446-2453

13 Henry LA, Witt DM. Resveratrol: phytoestrogen effects on reproductive physiology and behavior in female rats. Horm Behav 2002; 41: 220-228

14 Adlercreutz $H$. Phytoestrogens: epidemiology and a possible role in cancer protection. Environ Health Perspect 1995; 103: 103-112

15 Mense SM, Hei TK, Ganju RK, Bhat HK. Phytoestrogens and breast cancer prevention: possible mechanisms of action. Environ Health Perspect 2008; 116: 426-433

16 Tamir S, Eizenberg M, Somjen D, Izrael S, Vaya J. Estrogen-like activity of glabrene and other constituents isolated from licorice root. J Steroid Biochem Mol Biol 2001; 78: 291-298

17 Kostelac D, Rechkemmer G, Briviba K. Phytoestrogens modulate binding response of estrogen receptors $\alpha$ and $\beta$ to the estrogen response element. J Agric Food Chem 2003; 51: 7632-7635

18 Kuiper GG, Lemmen JG, Carlsson B, Corton JC, Safe SH, van der Saag PT, van der Burg B, Gustafsson JA. Interaction of estrogenic chemicals and phytoestrogens with estrogen receptor $\beta$. Endocrinology 1998; 139 : 4252-4263

19 Boué SM, Wiese TE, Nehls S, Burow ME, Elliott S, Carter-Wientjes CH, Shih $B Y$, McLachlan JA, Cleveland TE. Evaluation of the estrogenic effects of legume extracts containing phytoestrogens. J Agric Food Chem 2003; 51: 2193-2199

20 Lee YM, Kim JB, Bae JH, Lee JS, Kim PS, Jang HH, Kim HR. Estrogen-like activity of aqueous extract from Agrimonia pilosa Ledeb. in MCF-7 cells. BMC Complement Altern Med 2012; 12: 260

21 Liu J, Burdette JE, Xu H, Gu C, van Breemen RB, Bhat KPL, Booth N, Constantinou AI, Pezzuto JM, Fong HHS, Farnsworth NR, Bolton JL. Evaluation of estrogenic activity of plant extracts for the potential treatment of menopausal symptoms. J Agric Food Chem 2001; 49: 2472-2479

22 Overk CR, Yao P, Chadwick LR, Nikolic D, Sun Y, Cuendet MA, Deng Y, Hedayat A, Pauli GF, Farnsworth NR. Comparison of the in vitro estrogenic activities of compounds from hops (Humulus lupulus) and red clover (Trifolium pratense). J Agric Food Chem 2005; 53: 6246-6253

23 Lee HY, Park SH, Chae SW, Soung NK, Oh MJ, Kim JS, Kim YO, Chae HJ. Aqueous ginseng extract has a preventive role in RANKL-induced osteoclast differentiation and estrogen deficiency-induced osteoporosis. J Funct Foods 2015; 13: 192-203

24 Zhu Y, Xu J, Li Z, Xie S, Zhou J, Guo X, Zhou X, Li G, Zhong R, Ma A. Ginsenoside $\mathrm{Rh} 2$ suppresses growth of uterine leiomyoma in vitro and in vivo and may regulate ER $\alpha / \mathrm{c}$-Src/p38 MAPK activity. J Funct Foods 2015; 18 (Part A): 73-82

25 Grube B, Walper A, Wheatley D. St. John's wort extract: efficacy for menopausal symptoms of psychological origin. Adv Ther 1999; 16: 177-186

26 Hunt E, Lester C, Lester E, Tackett R. Effect of St. John's wort on free radical production. Life Sci 2001; 69: 181-190

27 Tripathi YB, Pandey E. Role of alcoholic extract of shoot of Hypericum perforatum Linn on lipid peroxidation and various species of free radicals in rats. Indian J Exp Biol 1999; 37: 567-571

28 Barnes J, Anderson LA, Phillipson JD. St John's wort (Hypericum perforatum L.): a review of its chemistry, pharmacology and clinical properties. J Pharm Pharmacol 2001; 53: 583-600
29 Chatterjee SS, Bhattacharya SK, Wonnemann M, Singer A, Müller WE. Hyperforin as a possible antidepressant component of hypericum extracts. Life Sci 1998; 63: 499-510

30 Koeberle A, Rossi A, Bauer J, Dehm F, Verotta L, Northoff H, Sautebin L, Werz 0 . Hyperforin, an anti-inflammatory constituent from St. John's wort, inhibits microsomal prostaglandin E2 synthase- 1 and suppresses prostaglandin E2 formation in vivo. Front Pharmacol 2011; 2: 7

31 Meruelo D, Lavie G, Lavie D. Therapeutic agents with dramatic antiretroviral activity and little toxicity at effective doses: aromatic polycyclic diones hypericin and pseudohypericin. Proc Natl Acad Sci U S A 1988; 85: 5230-5234

32 Butterweck V. Mechanism of action of St John's wort in depression. CNS Drugs 2003; 17: 539-562

33 Liu YR, Xiao BK, Yang JY, Guo CH, Shen SJ, Tang ZS, Dong JX, Huang RQ. ${ }^{1} \mathrm{H}-\mathrm{NMR}$ and HPLC-MS/MS-based global/targeted metabolomic evaluation of Hypericum perforatum L. intervention for menopause. J Funct Foods 2015; 17: 722-741

34 Harris D, Besselink E, HenningS, Go V, HeberD. Phytoestrogens induce differential estrogen receptor alpha- or beta-mediated responses in transfected breast cancer cells. Exp Biol Med (Maywood) 2005; 230: 558-568

35 Wakeling $A E$, Dukes $M$, Bowler J. A potent specific pure antiestrogen with clinical potential. Cancer Res 1991; 51: 3867-3873

36 Howell A, Osborne CK, Morris C, Wakeling AE. ICI 182, 780 (Faslodex ${ }^{\mathrm{TM}}$ ). Cancer 2000; 89: 817-825

37 Lucas TFG, Royer C, Siu ER, Lazari MFM, Porto CS. Expression and signaling of G protein-coupled estrogen receptor 1 (GPER) in rat Sertoli cells. Biol Reprod 2010; 83: 307-317

38 Royer C, Lucas TFG, Lazari MFM, Porto CS. 17Beta-estradiol signaling and regulation of proliferation and apoptosis of rat Sertoli cells. Biol Reprod 2012; 86: 108

39 Rochefort H, Garcia M, Glondu M, Laurent V, Liaudet E, Rey JM, Roger P. Cathepsin D in breast cancer: mechanisms and clinical applications, a 1999 overview. Clin Chim Acta 2000; 291: 157-170

40 Fung K, Samara E, Wong C, Metwalli A, Krlin R, Bane B, Liu C, Yang J, Pitha $J$, Culkin D. Increased expression of type $23 \alpha$-hydroxysteroid dehydrogenase/type 5 17 $\beta$-hydroxysteroid dehydrogenase (AKR1C3) and its relationship with androgen receptor in prostate carcinoma. Endocr Relat Cancer 2006; 13: 169-180

41 Rižner TL, Penning TM. Role of aldo-keto reductase family 1 (AKR1) enzymes in human steroid metabolism. Steroids 2014; 79: 1-37

42 McCarty MF, Barroso-Aranda J, Contreras F. Genistein and phycocyanobilin may prevent hepatic fibrosis by suppressing proliferation and activation of hepatic stellate cells. Med Hypotheses 2009; 72: 330-332

43 Ambruso DR, Ellison MA, Thurman GW, Leto TL. Peroxiredoxin 6 translocates to the plasma membrane during neutrophil activation and is required for optimal NADPH oxidase activity. Biochim Biophys Acta 2012; 1823: 306-315

44 Nadal-Serrano M, Sastre-Serra J, Pons DG, Miro AM, Oliver J, Roca P. The ERalpha/ERbeta ratio determines oxidative stress in breast cancer cell lines in response to 17Beta-estradiol. J Cell Biochem 2012; 113: 3178-3185

45 Compton DA, Luo C. Mutation of the predicted p34cdc2 phosphorylation sites in NuMA impair the assembly of the mitotic spindle and block mitosis. J Cell Sci 1995; 108: 621-633

46 Cirak C, Radusiene J, Stanius Z, Camas N, Caliskan O, Odabas MS. Secondary metabolites of Hypericum orientale L. growing in Turkey: variation among populations and plant parts. Acta Physiol Plant 2012; 34: 1313 1320

47 Felekkis KN, Narsimhan RP, Near R, Castro AF, Zheng Y, Quilliam LA, Lerner $A$. AND-34 activates phosphatidylinositol 3-kinase and induces anti-estrogen resistance in a SH2 and GDP exchange factor-like domain-dependent manner. Mol Cancer Res 2005; 3: 32-41

48 Mirebeau-Prunier D, Le Pennec S, Jacques C, Gueguen N, Poirier J, Malthiery $Y$, Savagner F. Estrogen-related receptor $\alpha$ and PGC-1-related coactivator constitute a novel complex mediating the biogenesis of functional mitochondria. FEBS J 2010; 277: 713-725

49 Chou J, Lin JH, Brenot A, Kim JW, Provot S, Werb Z. GATA3 suppresses metastasis and modulates the tumour microenvironment by regulating microRNA-29b expression. Nat Cell Biol 2013; 15: 201-213

50 Nakagawa Y, Suzuki T, Tayama S. Metabolism and toxicity of benzophenone in isolated rat hepatocytes and estrogenic activity of its metabolites in MCF-7 cells. Toxicology 2000; 156: 27-36

51 Jeong EH, Vaidya B, Cho SY, Park MA, Kaewintajuk K, Kim SR, Oh MJ, Choi JS, Kwon J, Kim D. Identification of regulators of the early stage of viral hemorrhagic septicemia virus infection during curcumin treatment. Fish Shellfish Immunol 2015; 45: 184-193 